\title{
PRODUÇÃO, BENEFICIAMENTO E COMERCIALIZAÇÃO DO CAMARÃO-DA-AMAZÔNIA A JUSANTE DA USINA HIDRELÉTRICA DE TUCURUÍ, ESTADO DO PARÁ, BRASIL
}

\author{
PRODUCTION, PROCESSING AND COMMERCIALIZATION OF THE \\ AMAZON RIVER PRAWN DOWNSTREAM TUCURUÍ DAM, PARÁ STATE, \\ BRAZIL
}

Israel Hidenburgo Aniceto Cintra ${ }^{1 *}$, Maria Vera Lúcia Ferreira de Araújo $^{2}$, Kátia Cristina de Araújo Silva $^{1}$, Déborah Elena Galvão Martins ${ }^{1}$, Janildo da Silva Aviz ${ }^{2}$, Maurício da Silva Bastos ${ }^{3}$ \& José Milton Barbosa ${ }^{4}$ ${ }^{1}$ Instituto Socioambiental e dos Recursos Hídricos, Universidade Federal Rural da Amazônia - UFRA ${ }^{2}$ Instituto Federal de Educação, Ciência e Tecnologia do Pará - IFPA

${ }^{3}$ Secretaria Municipal de Educação de Cametá - Semed 4Departamento de Engenharia de Pesca e Aquicultura, Universidade Federal de Sergipe - UFS

*E-mail: israel.cintra@ufra.edu.br

\begin{abstract}
RESUMO Este estudo descreve a produção, produtos obtidos, beneficiamento e comercialização do camarão-da-amazônia capturado a jusante da usina hidrelétrica de Tucuruí. A coleta de dados foi realizada por meio de informações de desembarques, observações diretas, conversas informais e entrevistas individuais, auxiliadas por formulários semiestruturados aplicados junto aos pescadores de camarão-da-amazônia nas residências (ilhas e/ou comunidade), feiras ou mercados municipais, no período de setembro a novembro de 2011, setembro de 2012 e setembro de 2017. A pesca do camarão-daamazônia é expressiva na área a jusante da UHE Tucuruí-PA, é uma atividade eminentemente artesanal, com produção que varia muito ao longo do ano, beneficiamento tradicional e familiar e geralmente comercializado localmente.
\end{abstract}

Palavras-chave: UHE Tucuruí, Camarão de água doce, pesca artesanal, valor agregado, camarão salgado.

\begin{abstract}
This study describe the production, products, processing and commercialization of the Amazon River prawn caught downstream Tucuruí dam. Data consists of landing information, direct observations, informal conversation, individual interviews applied to fishermen with semi-structured forms. Interviews occurred at their residences (islands or communities) or markets, from September to November 2011 and from September 2012 to September 2017. Amazon River prawn fishery is expressive downstream Tucuruí dam, it is an artisanal activity, with variable production along the year. Processing is traditional and familiar and the production is, in general, commercialized locally.
\end{abstract}

Key words: Tucuruí damn, freshwater prawn, artisanal fishing, value-added, salted prawn. 


\section{Introdução}

A Usina Hidrelétrica de Tucuruí (UHE Tucuruí) que abrange na sua área de influência os municípios de Marabá, Itupiranga, Nova Ipixuna, Jacundá, Goianésia do Pará, Novo Repartimento, Breu Branco, Tucuruí, Baião, Mocajuba, Cametá e Limoeiro do Ajuru (Cintra, Flexa, Silva, Araújo \& Silva, 2013), apresenta a maior produção de pescado, oriundo da pesca extrativa continental, dentre as hidrelétricas da Região Amazônica.

A área de influência desta UHE apresenta uma rica fauna aquática (Mérona, Santos, Juras \& Cintra, 2010) composta, principalmente por peixes e camarões, alvo das capturas dos pescadores artesanais, com destaque para o mapará Hypophthalmus marginatus Valenciennes, 1840, as pescadas Plagioscion squamosissimus (Heckel, 1840) e Plagioscion auratus (Castelnau, 1855), os tucunarés Cichla monoculus Spix \& Agassiz, 1831 e Cichla sp., a curimatá Prochilodus nigricans Agassiz, 1829, a jatuarana Hemiodus unimaculatus (Bloch, 1794), o acará-tinga Geophagus proximus (Castelnau, 1855), as branquinhas Curimata inornata Vari, 1989 e Curimata vittata (Kner, 1858), os piaus Schizodon vittatum (Valenciennes, 1849), Anostomoides laticeps (Eigenmann, 1912), Laemolyta petiti Géry, 1964) e o jaraqui Semaprochilodus brama (Valenciennes, 1850), a montante da UHE Tucuruí, e o mapará Hypophthalmus marginatus Valenciennes, 1840 e o camarão-daamazônia Macrobrachium amazonicum (Heller, 1862) a jusante da UHE Tucuruí (Cintra, Juras, Andrade \& Ogawa, 2007), especialmente o camarão-da-amazônia que é muito bem aceito pelos consumidores e apreciado em toda Amazônia, pois sua carne apresenta textura mais firme e sabor mais acentuado quando comparado com outros camarões de água doce (Lima et al., 2016).

Este trabalho aborda a produção, o beneficiamento e a comercialização do camarão-da-amazônia, nos principais municípios produtores na área de influência da UHE Tucuruí, descreve o beneficiamento e os produtos que são elaborados e visa fornecer contribuições para o desenvolvimento de ferramentas tecnológicas que podem melhorar a qualidade dos produtos elaborados, agregando valor ao camarão-da-amazônia.

\section{Material e Métodos}

\section{CARACTERIZAÇÃO DA ÁREA}

A UHE Tucuruí está localizada no canal principal do rio Tocantins ( $03^{\circ} 49^{\prime} 54,00^{\prime \prime} \mathrm{S}$ e $\left.49^{\circ} 38^{\prime} 48,00^{\prime \prime} \mathrm{W}\right)$, no município de Tucuruí - PA. A sua área de influência pode ser dividida em três subáreas: montante, reservatório e jusante. O clima, na região de Tucuruí, é marcado por dois períodos bem definidos: o chuvoso, que se estende de dezembro a maio, com precipitações atingindo valores entre $500-600 \mathrm{~mm} / \mathrm{mês}$ e o menos chuvoso, que ocorre de junho a novembro, quando a precipitação é da ordem de $30 \mathrm{~mm} / \mathrm{mês}$ (Fisch, Januário \& Senna, 1990; Sanches \& Fisch, 2005).

A área à montante da UHE Tucuruí localiza-se acima da porção terminal do reservatório e ao início do leito normal do rio Tocantins, abrangendo os municípios de Marabá e Itupiranga (Santos \& Mérona, 1996). Reservatório é a zona de inundação que chega até um pouco antes da cidade de Itupiranga, situada a $170 \mathrm{~km}$ a montante. Compreende as áreas de desembarque localizadas em Nova Ipixuna, Jacundá, Goianésia do Pará, Novo Repartimento, Breu Branco e Tucuruí (Porto do Quilômetro 11) (Juras, Cintra \& Ludovino, 2004). A área a jusante pertence à Mesorregião do Nordeste Paraense e à Microrregião de Cametá, situado no Baixo rio Tocantins, abrangendo os municípios de Baião, Mocajuba, Cametá e Limoeiro do Ajuru, onde ocorre o encontro entre os rios Tocantins e Pará

\section{COLETA DE DADOS}

Os dados coletados por meio de pesquisa em campo no período de setembro a novembro de 2011, setembro de 2012 e setembro de 2017, à jusante da UHE Tucuruí, com utilização da metodologia descrita por Pereira, Shitsuka, Parreira \& Shitsuka (2018), que consta de observações diretas e entrevistas individuais, auxiliadas por formulários semiestruturados aplicados aos pescadores de camarão-da-amazônia, nas residências (ilhas e/ou comunidade), feiras e mercados municipais. Durante o período da coleta de dados foram obtidas 243 entrevistas, distribuídas nos municípios mais destacados: 58 em Baião, 60 em Mocajuba, 65 em Cametá e 60 em Limoeiro do Ajuru.

As informações referentes aos desembarques foram fornecidas pelo Programa de Pesca e Ictiofauna das Centrais Elétricas do Norte do Brasil S/A - Eletronorte, que realizou um programa contínuo de coleta de dados nos portos de desembarques dos municípios da região, no período de 2000 a 2008. 
Os dados de desembarques foram analisados por município, mês e ano, com exclusão do município de Tucuruí que apresentou informações insuficientes para o objeto de estudo. Posteriormente, comparou-se os resultados com o conhecimento tradicional dos pescadores, apontados nos formulários semiestruturados.

Para o entendimento da frequência de pesca adotou-se o termo "diário" para os profissionais que informaram pescar camarões diariamente ou que param suas atividades em curtos períodos de tempo, como nos finais de semana, feriados e marés de sizígia (as marés de sizígia são marés que ocorrem nas luas nova e cheia, produzindo as maiores marés altas e as menores marés baixas, respectivamente). O termo "safra" foi adotada para abranger os pescadores que exercem a pesca apenas no período de maior abundância do crustáceo.

As informações sobre o beneficiamento, estocagem e comercialização do crustáceo foram obtidas mediante conversas informais e observações in loco, a fim de descrever o processo produtivo e entender como ocorre a venda de produtos elaborados.

A unidade de medida adotada pelos pescadores "frascos" foi transformada em quilograma, com o auxílio de uma balança digital, para melhor compreensão dos preços dos produtos.

\section{Resultados e Discussão}

Nas regiões ribeirinhas do norte do Brasil o camarão-da-amazônia se destaca pela sua importância econômica e social, e por ser para alguns municípios a principal fonte de emprego e renda. Sendo consumido tradicionalmente no Amapá e no Pará e encontrado nos mercados do Amazonas, Rondônia, Roraima e Acre (Lima; Cintra; Bastos; Damasceno; Montagner \& Varela, 2016).

Apesar da sua visível importância, os diversos apetrechos e procedimentos de pesca, estatística de produção, métodos de conservação e as cadeias produtiva e de comercialização do camarão-da-amazônia ainda são pouco conhecidos.

A captura na região Amazônica é realizada exclusivamente por pescadores artesanais e ribeirinhos de diversas localidades de áreas continentais e estuarinas, incluindo ilhas do Amapá e do Pará (Lima; Santos, 2014). E que a pesca, beneficiamento e comercialização do camarão-da-amazônia é uma atividade familiar, sendo praticada por crianças, jovens, adultos e idosos (Araújo; Silva; Silva; Ferreira; \& Cintra, 2014).

\section{PRODUÇÃO PESQUEIRA}

A produção comercial de camarão-da-amazônia é significativa apenas no trecho de jusante da área de influência da UHE Tucuruí, com destaque para o município de Mocajuba que durante o período de 2000 a 2008, desembarcou uma média anual de $38.128 \mathrm{~kg}$ desse crustáceo, com variação de $12.433 \mathrm{~kg}$, em $2001 \mathrm{a}$ 89.377 kg, em 2006. Os municípios de Cametá, Limoeiro do Ajuru e Baião tiveram uma contribuição média anual de $17.019 \mathrm{~kg}, 11.840 \mathrm{~kg}$ e $7.800 \mathrm{~kg}$, respectivamente. Parte do município de Tucuruí, que também engloba a área a jusante da usina, registrou $3.532 \mathrm{~kg}$ no ano de 2001, $9 \mathrm{~kg}$ em 2008 e nos demais anos não houve registros (Tabela 1).

Tabela 1 - Produção anual (kg) de por município da área a jusante da UHE Tucuruí, no período de 2000 a 2008 (Fonte: Centrais Elétricas do Norte do Brasil S/A - Eletronorte).

\begin{tabular}{ccccccc}
\hline & \multicolumn{5}{c}{ Município/ Área } \\
\cline { 2 - 7 } Ano & Tucurú & Baião & Mocajuba & Cametá & Limoeiro do Ajuru & Jusante \\
\hline 2000 & 0 & 0 & 14.837 & 7.913 & 0 & 22.750 \\
2001 & 3.532 & 11.057 & 12.433 & 26.285 & 0 & 53.307 \\
2002 & 0 & 15.820 & 28.271 & 24.226 & 10.781 & 79.098 \\
2003 & 0 & 18.283 & 23.870 & 31.256 & 16.318 & 89.727 \\
2004 & 0 & 13.387 & 18.491 & 15.458 & 15.284 & 62.619 \\
2005 & 0 & 3.403 & 70.537 & 14.175 & 20.234 & 108.349 \\
2006 & 0 & 2.749 & 89.377 & 9.850 & 17.706 & 119.682 \\
2007 & 0 & 2.054 & 43.776 & 9.892 & 16.166 & 71.888 \\
2008 & 9 & 3.444 & 41.560 & 14.114 & 10.071 & 69.198 \\
\hline
\end{tabular}

Ao analisar a área a jusante da barragem (com exceção de Tucuruí), observou-se a alta frequência de desembarque no baixo Tocantins, com grande variação mensal, com picos nos meses de maio e novembro, 
ocorridos em Baião, Mocajuba e Cametá. No município de Limoeiro do Ajuru houve um segundo pico de produção, no mês de agosto. No entanto, quando se analisa os dados de desembarque de jusante fica claro que nessa subárea existe uma safra com um grande pico de produção em maio (final do inverno) e uma baixa em novembro (final do verão) (Figura 1).

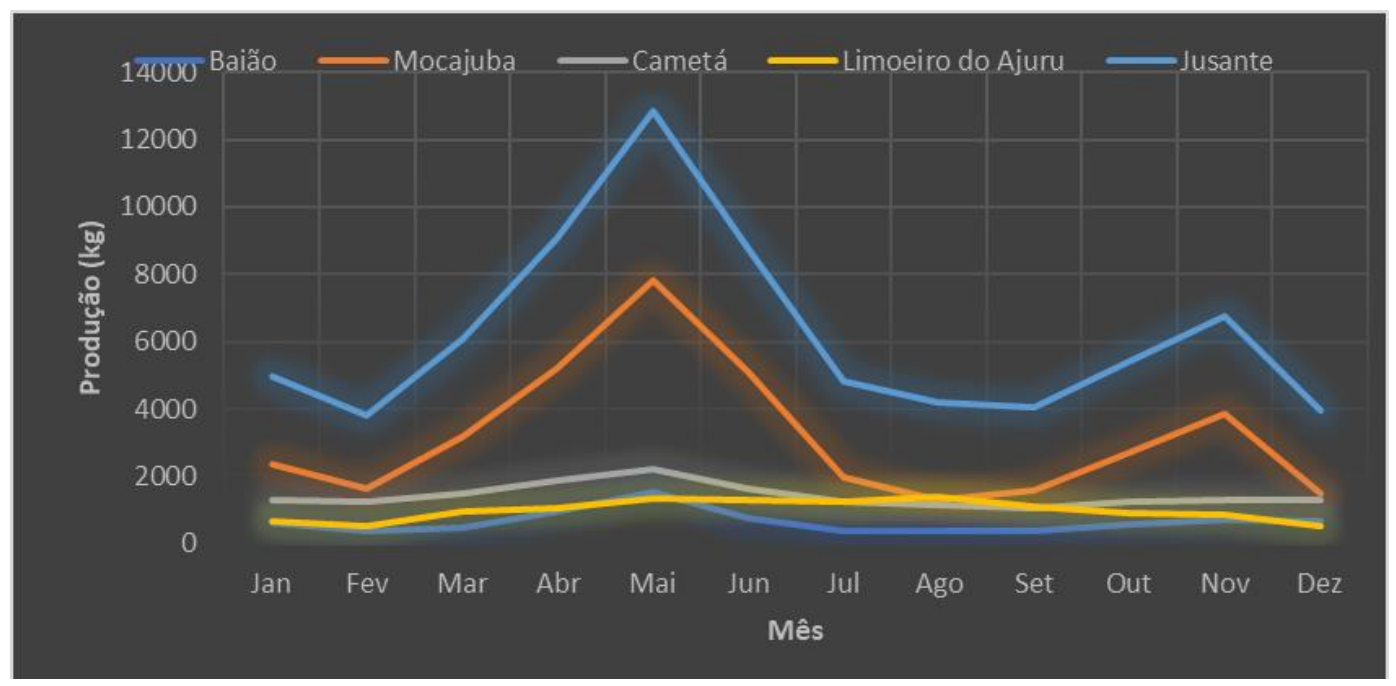

Figura 1. Produção mensal média (kg) de camarão por local de estudo no período de 2000 a 2008 na área de influência da UHE Tucuruí, estado do Pará (Fonte: Centrais Elétricas do Norte do Brasil S/A - Eletronorte).

Informações obtidas de pescadores de camarão, da Vila Bereca (município de Baião) apontam que pesca camarão todos os dias, há 26 anos e com toda a produção direcionada para a venda, confirmam a existência de duas safras bem distintas na região. Porém, $79 \%$ dos entrevistados informaram que o inverno é a melhor estação para pescar camarão. Deste total, $62 \%$ relacionaram esse período com a abundância do recurso e $33 \%$ justificaram essa temporada como sendo não somente a de maior abundância, como também apresentam camarões de maior porte, os demais não souberam informar.

Nos municípios de Baião e Mocajuba, 78\% dos pescadores entrevistados consideram o inverno como sendo o período de safra, pelas vantagens das capturas em quantidade e qualidade (camarões graúdos), já o verão ocorre a entressafra, pela escassez e redução da produção e do tamanho dos animais. Os pescadores argumentam que a safra é favorecida pela incidência de chuvas que propicia a elevação do nível do rio que invade o interior das ilhas, ampliando assim, as áreas de pesca o que acaba beneficiando os pescadores que, ademais, passam a pescar camarão nos igarapés próximo as suas residências. No entanto, em Limoeiro do Ajuru ocorre o contrário, $60 \%$ informaram que o verão é a melhor estação de pesca, sendo, este o período de safra na região, favorecido pela baixa incidência de chuvas e consequente concentração dos camarões no leito do rio.

A sazonalidade do recurso em questão influencia diretamente no esforço de pesca, constatado pelos $57 \%$ dos profissionais pescam diariamente, os demais (43\%) pescam sapenas no período de maior abundância do crustáceo

Nos municípios de Baião e Mocajuba o incremento do número de pescadores, durante o período de safra, não chega a 50\%, porém, em Cametá gira em torno de $58 \%$ e em Limoeiro do Ajuru cresce apenas 17\%, pois nesse município a grande maioria dos pescadores atuam diariamente. Os "pescadores de safra" da área de jusante alegam que não compensa pescar camarão na entressafra porque é difícil captura-los, em função do pequeno porte dos crustáceos. Talvez as dificuldades de captura estejam ligadas ao tipo de matapi usado (Figura 2), haja vista que em Baião alguns pescadores utilizam dois tipos de matapis,

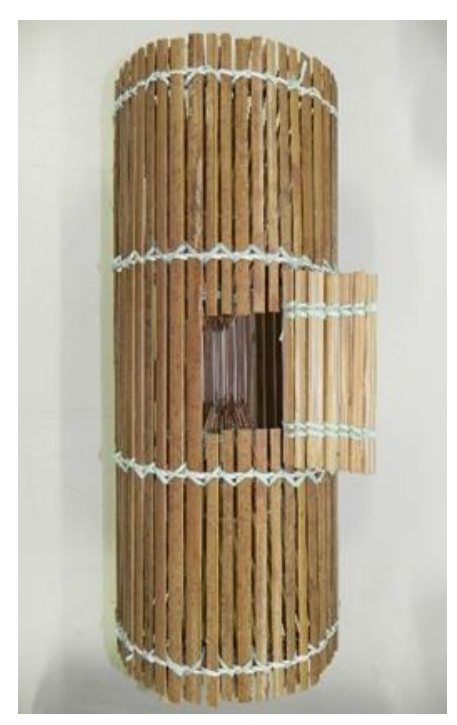

Figura 2. Matapi, petrecho utilizada na pesca do camarão-da-amazônia Macrobrachium amazonicum na Usina Hidroelétrica de Tucuruí, Estado do Pará.

confeccionados de acordo com o tamanho do camarão. Durante a safra é comum o uso do apetrecho denominado de "matapi de inverno", confeccionado para capturar camarão graúdo (espaçamento entre talas é 
maior), que é abundante nesse período do ano. No entanto, entre os profissionais que continuam pescando na entressafra, alguns passam a usar o "matapi de verão", fabricado com espaçamento entre talas menor em relação ao apetrecho anterior, a fim de reter o camarão miúdo dentro das armadilhas, pois de acordo com os pescadores, nessa estação do ano o camarão "miúdo" é abundante na região.

Alguns pescadores relataram que na safra, com 100 matapis captura-se no máximo 20 frascos $(20 \mathrm{~kg}) \mathrm{de}$ camarão graúdo por dia. E na entressafra, com a mesma quantidade de matapis, é possível capturar até 40 frascos (40 kg) de camarão miúdo por dia.

Com relação à importância social da atividade, destaca-se o desenvolvimento da pesca de camarão com o objetivo de obter alimento e renda por $85 \%$ dos pescadores de jusante. Entre os municípios, Mocajuba apresentou o maior percentual de pescadores (97\%) que distribuem sua produção entre o consumo e a venda. E 22\% dos cametaenses declararam que pescam camarão somente para o consumo da família. O município de Baião contabilizou os maiores percentuais (13\%) de pescadores que afirmaram pescar para comercializar o produto (Figura 3).

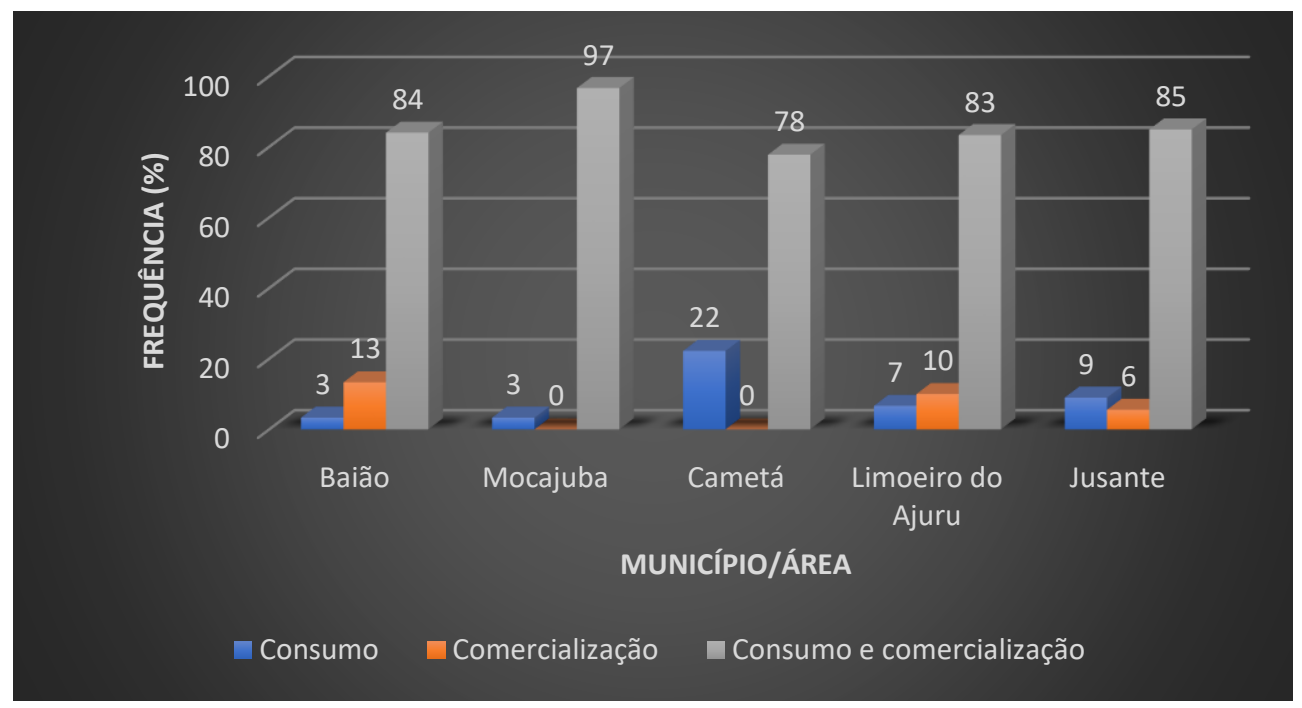

Figura 3. Frequência da destinação do produto da pesca do camarão-da-amazônia, por local amostrado da área à jusante da UHE Tucuruí, Estado do Pará, no período de setembro a novembro de 2011 e setembro de 2012.

Os dados de desembarque mostram claramente a importância comercial do camarão-da-amazônia para área de jusante, nas demais áreas como no reservatório, o recurso é usado somente como isca (Cintra; Juras; Silva; Tenório \& Ogawa, 2009). A falta de interesse comercial por esse crustáceo a montante da barragem se deve, provavelmente, ao tamanho dos exemplares capturados, haja vista, que

a população do reservatório apresenta em média comprimentos menores aos dos camarões das águas correntes do trecho de jusante (Odinetz-Collart, 1988).

Ao analisar os picos de produção da espécie percebe-se a incidência dos animais nos períodos de reprodução e recrutamento do camarão. Silva, Cintra e Muniz (2005) citam que o camarão-da-amazônia é uma espécie muito frequente na área a jusante da barragem, com produção elevada e maior intensidade reprodutiva ocorridos durante a estação chuvosa, para estudos realizados em Cametá. Odinetz-Collart (1993) também constatou a reprodução sazonal do crustáceo, com desovas maciças no meio da vazante (maio/julho), para o mesmo local de estudo.

No entanto, em Cametá o período menos chuvoso está intimamente relacionado com o recrutamento da espécie, principalmente nos meses de agosto, setembro e novembro (Silva, Cintra \& Muniz, 2005). De acordo com Fonteles-Filho (2011), o recrutamento ocorre quando os indivíduos jovens de uma coorte, ao atingirem o comprimento médio na maturidade sexual $\left(\mathrm{L}_{50}\right)$, incorporam ao estoque reprodutor.

Quanto ao conhecimento tradicional da sazonalidade do recurso, nota-se que tais saberes aprimorados pela experiência de vida dos pescadores corroboram com as análises de Odinetz-Collart (1993), sobre a ocorrência da safra do recurso entre os meses de maio e junho, além de associar esse fenômeno (safra) a intensidade da cheia ocorrida três meses antes. Segundo a autora, a enchente ocasiona mudanças favoráveis à sobrevivência e crescimento do camarão-da-amazônia, pois, propicia a expansão das macrófitas aquáticas que contribui com 
a redução da competição intraespecífica, aumentando a quantidade de micro-habitats para as larvas, além de aportar material em suspensão incrementando a produtividade dos lagos de várzea.

Por outro lado, as características peculiares ao município de Limoeiro do Ajuru corroboram os resultados apontados por Silva, Bentes, Cañete, Pereira, Martinelli-Lemos \& Isaac (2012), para a ilha do Mosqueiro, estado do Pará, que demonstram a ocorrência da safra no período seco e a entressafra na estação chuvosa. Provavelmente, esta coincidência esteja relacionada a fatores ambientais comuns aos dois locais estudados, como a dinâmica do rio Pará, por exemplo, que durante a preamar invade o rio Tocantins. No entanto, a influência das marés sobre o rio Tocantins reduz à medida que se aproxima da barragem, com amplitudes em torno de 4 m em Cametá e 1 m na região de Icangui, estado do Pará (Odinetz-Collart, 1988).

Outro fator a ser levado em consideração, é o fato dos picos de produção evidenciados para Limoeiro do Ajuru terem ocorridos praticamente na mesma estação do ano, ou seja, em maio, mês de transição entre o inverno e o verão e em agosto, no meio do verão, o que possivelmente influenciou na resposta apresentada pela maioria dos entrevistados.

Quanto ao esforço de pesca, destaca-se que a dedicação sazonal dos pescadores à pesca, também foi apontada por Silva et al. (2012) para a ilha do Mosqueiro e por Odinetz-Collart (1993) para Cametá, onde se atribuiu a variação sazonal do esforço de pesca ao número de matapis/mês.

Os resultados revelam que mesmo utilizando a mesma quantidade de matapis, as capturas mais produtivas, por pescador, ocorrem na entressafra, fato que pode ser justificado pelo aumento do esforço de pesca durante a safra e redução do esforço de pesca na entressafra, associado ao uso de apetrechos pouco seletivos. Simonian (2006) relata nos estudos realizados para o município de Barcarena (PA), que a quantidade capturada por pescador varia substancialmente em função do número de matapis usado, do tempo de trabalho destinado à pesca, da experiência do pescador e das condições locais de produção (abundância do produto e pesca intensiva). Tais fatores também foram constatados para a área a jusante da barragem de Tucuruí.

\section{PRODUTOS E BENEFICIAMENTO}

Dentre os produtos ofertados do camarão-da-amazônia destacam-se quatro tipos: a) Camarão inteiro fresco, cauda de camarão descascada refrigerada, camarão inteiro salgado e cauda de camarão descascada salgada (Figura 4). Mais de metade dos pescadores (63\%) comercializam o camarão inteiro fresco (sem beneficiamento), $22 \%$ beneficiam toda sua produção e $15 \%$ vendem o crustáceo das duas formas.

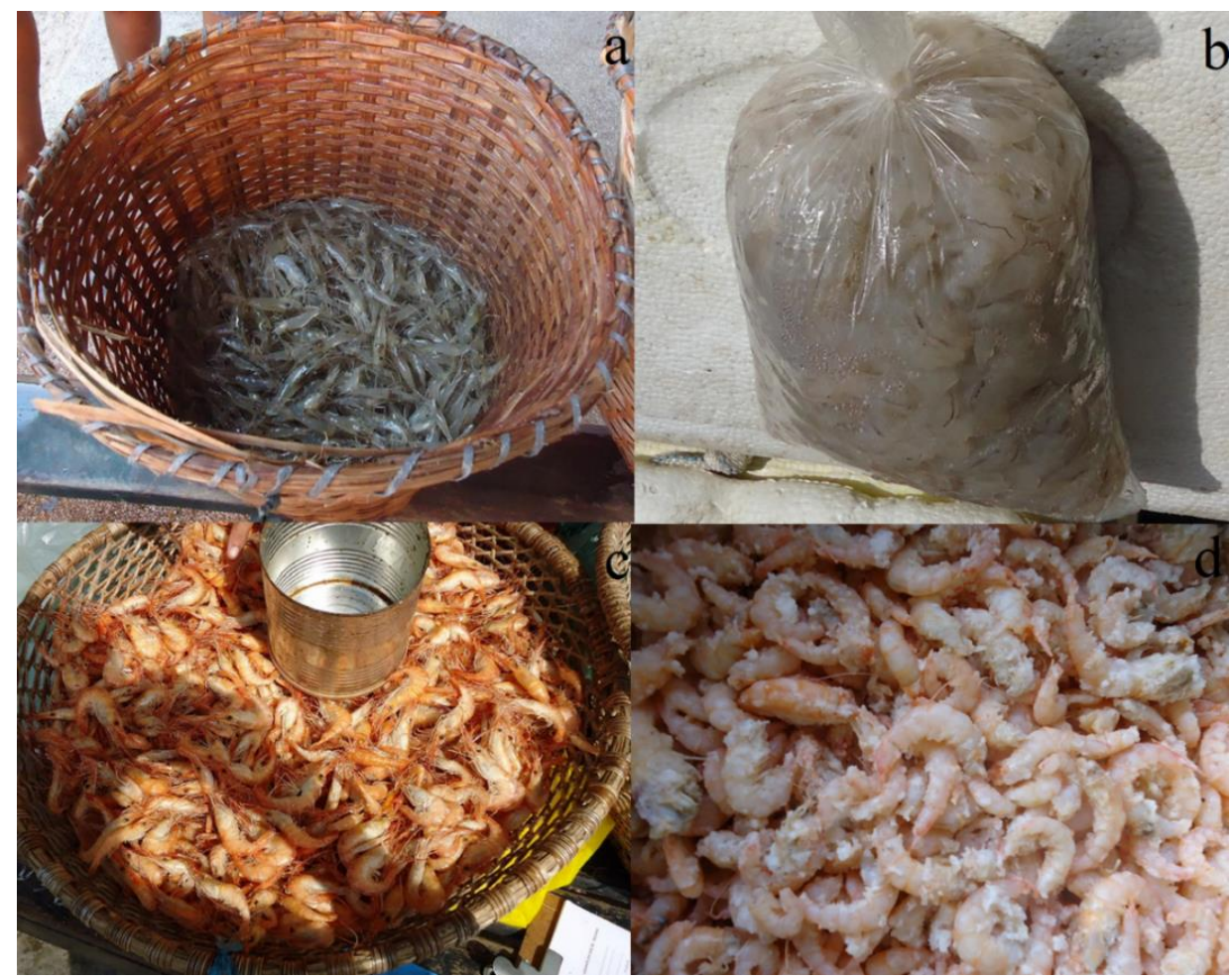

Figura 4. Produtos artesanais elaborados do camarão-da-amazônia: a) camarão inteiro fresco, b) cauda de camarão descascada refrigerada ("Polpa"), c) camarão inteiro salgado ("frito"), e d) cauda de camarão descascada salgada ("salgadinho") na área a jusante da barragem da UHE Tucuruí, estado do Pará. 
Com relação aos municípios, Baião e Limoeiro do Ajuru contam com o maior número de pescadores (cerca de 60\%) que beneficiam toda ou parte da produção destinada a venda, na forma de camarão inteiro salgado (conhecido localmente como "camarão frito") e de cauda de camarão descascada salgada (popularmente conhecida como "salgadinho").

O produto mais comercializado pelos pescadores, o camarão inteiro fresco, é comercializado sem nenhum beneficiamento. Sendo apresentado ao consumidor exposto, dentro de recipientes vazados, denominados paneiros (Figura 4a), sendo comum encontrar camarões ainda vivos. A partir do camarão fresco é elaborado o camarão descascado refrigerado, que consiste na retirada da carapaça (casca) do crustáceo, com aproveitamento do abdome (cauda), conhecido popularmente como polpa. O produto final é embalado em sacos plásticos de $1 \mathrm{~kg}$ e estocados em refrigerador doméstico (congelador) (Figura 4b).

O processo de beneficiamento inicia com o abate do camarão, imediatamente após a despesca dos matapis ou depois do acúmulo dos camarões nos viveiros, pois essa é a forma que os pescadores encontraram para estocar o produto, haja vista, que mais da metade dos profissionais não possuem geladeiras e tampouco freezer para conservá-los. O método de abate empregado depende do produto que será elaborado, podendo ser por choque térmico (na salmoura aquecida) ou de forma natural.

Para elaborar o camarão inteiro salgado os pescadores colocam o crustáceo em uma panela com água acrescida de sal (salmoura) e leva-os ao fogo. O tempo de cozimento e a quantidade de sal são variáveis e o cozimento é finalizado quando a coloração do crustáceo é alterada, associado ao cheiro típico, sendo logo após escorrido. Este beneficiamento é feito em lugares denominados pelos pescadores "locais de fritura". O produto não é embalado, ficando exposto durante a comercialização e a estocagem, pois são armazenados em paneiros, em temperatura ambiente.

O camarão descascado salgado é produzido a partir da retirada total da carapaça (casca) do produto, com aproveitamento abdome (cauda) que é envolvido em sal, para manter a conservação do produto. Os pescadores utilizam sacos plásticos de $1 \mathrm{~kg}$ para embalar o produto. Enquanto se junta uma quantidade suficiente para ser comercializada, os camarões são estocados em recipientes de alumínio ou plástico e mantidos em temperatura ambiente.

Ressalta-se ainda, que alguns pescadores utilizam o quilograma $(\mathrm{kg})$ como unidade de medida, mas a maioria utiliza um recipiente no formato de um cilindro circular reto, denominado "frasco", para medir a quantidade de camarão comercializada. O frasco com camarão inteiro fresco corresponde a um quilograma (Tabela 2).

Tabela 2 - Relação entre a principal unidade de medida utilizada pelos pescadores de camarão-da-amazônia a jusante da UHE Tucuruí, estado do Pará e o valor correspondente em quilograma ( $\mathrm{kg}$ ), no período de setembro a novembro de 2011 e setembro de 2012.

\begin{tabular}{lcc}
\hline & \multicolumn{2}{c}{ Unidade de medida } \\
\cline { 2 - 3 } \multicolumn{1}{c}{ Produto } & Frasco & Peso \\
\hline Camarão inteiro salgado & 1 & $600 \mathrm{~g}$ \\
Camarão descascado salgado & 1 & $800 \mathrm{~g}$ \\
Camarão inteiro fresco & 1 & $1.000 \mathrm{~g}$ \\
Camarão descascado refrigerado & 1 & $1.200 \mathrm{~g}$ \\
\hline
\end{tabular}

Os pescadores do baixo Tocantins, por meio de seu conhecimento empírico, produzem vários subprodutos oriundos do camarão-da-amazônia, impulsionados pela cultura da família ou orientados pela demanda de mercado. As etapas de produção são similares às de algumas regiões do estado bem como as denominações dos produtos elaborados. As pescadoras da ilha Trambioca (Barcarena, estado do Pará), por exemplo, também elaboram o "camarão frito", usando a mesma técnica descrita no presente estudo, divergindo somente na última etapa do processo que consiste na secagem do produto (Simonian, 2006).

\section{COMERCIALIZAÇÃO}

À jusante da barragem da UHE Tucuruí o camarão-da-amazônia é comercializado, em sua maioria, pelo próprio pescador (a) (66\%) seguido da esposa (o) (18\%) e também há uma pequena participação dos filhos. No geral, o recurso é vendido na feira/mercado municipal, principalmente nos municípios de Mocajuba 
(100\%), Baião (93\%) e Cametá (68\%). Em Limoeiro do Ajuru, mais da metade dos pescadores (53\%) comercializam o crustáceo em seus domicílios (Figura 5). Este município também apresentou o maior número de pescadores $(43 \%)$ que entregavam a produção apenas aos atravessadores, os quais dirigem-se até a feira/mercado municipal ou residência do profissional para negociar o camarão.

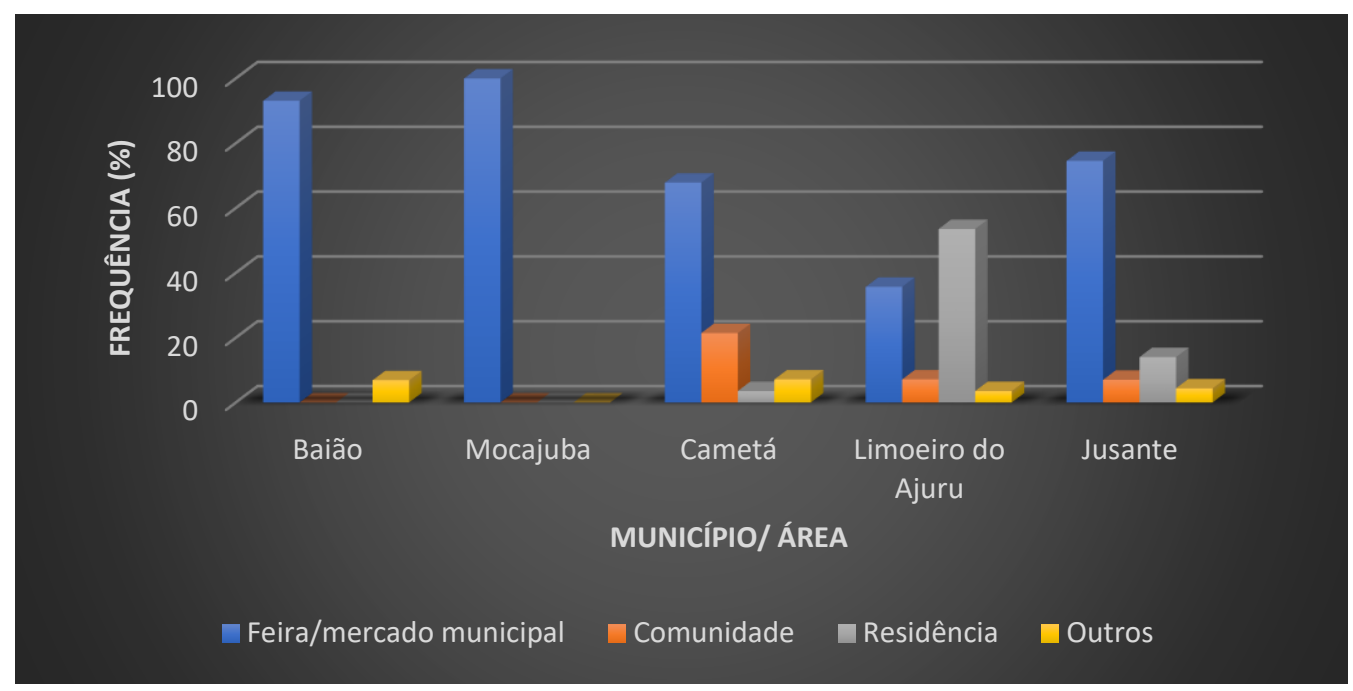

Figura 5. Frequência de locais de comercialização/desembarque do camarão-da-amazônia, nos municípios à jusante da UHE Tucuruí, estado do Pará.

No geral observou-se que na área à jusante, $69 \%$ dos pescadores vendiam seus produtos diretamente aos consumidores, alegando como principal motivo a obtenção de maiores lucros quando comparado aos valores pagos pelos atravessadores (Figura 6).

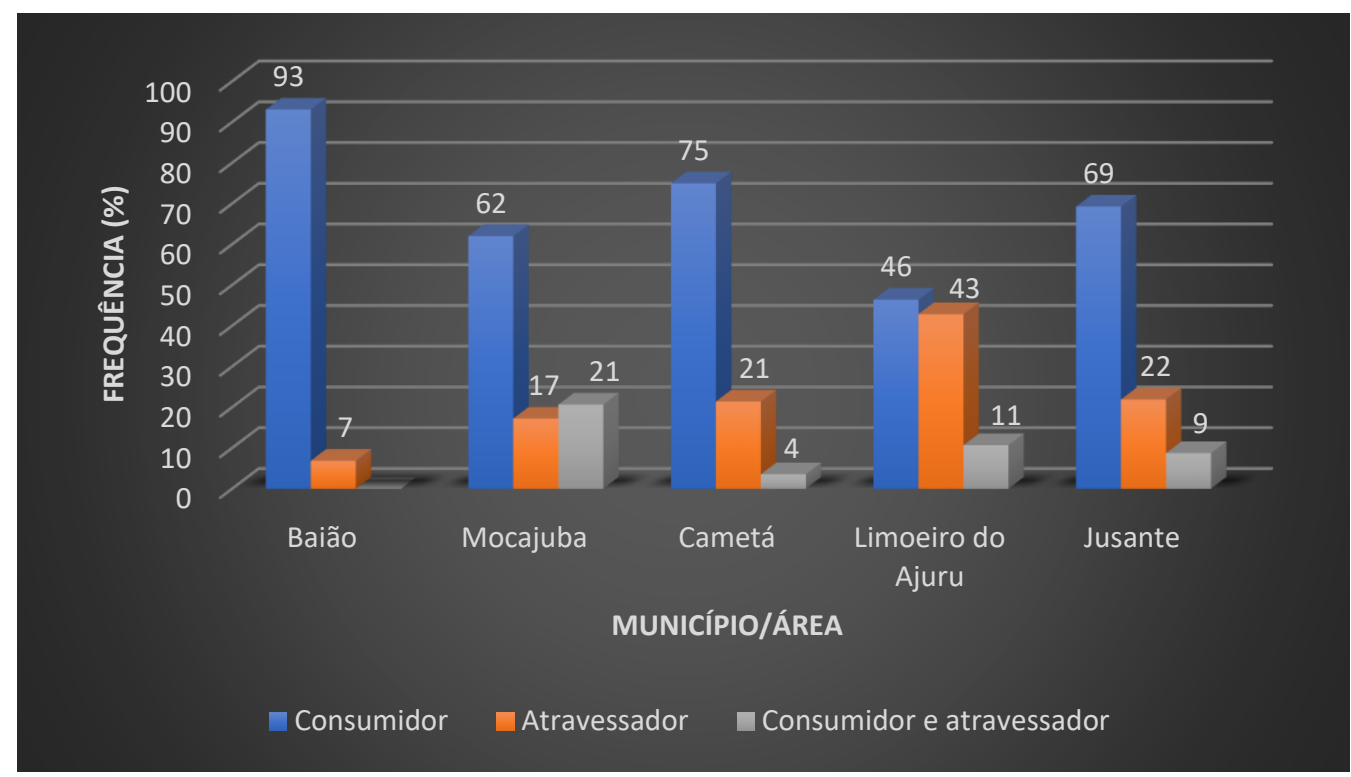

Figura 6. Relação dos compradores de camarão-da-amazônia por município da área a jusante da UHE Tucuruí, Estado do Pará.

Observou-se ainda, que metade da produção de camarão-da-amazônia ficava nos locais de captura, pois faz parte da cultura gastronômica da população local, a outra parcela é destinada a outros municípios paraense como Belém, Abaetetuba, Tucuruí, Marabá e outros estados como Rio de Janeiro e São Paulo. Geralmente o pagamento é efetuado em dinheiro, no ato da entrega do produto. No entanto, um pescador de Baião informou que comercializava o crustáceo em troca de mercadorias.

$\mathrm{O}$ valor pago pelo camarão varia significativamente com a sazonalidade do recurso e o tipo de produtos comercializados. Desta maneira, observou-se que $1 \mathrm{~kg}$ de camarão inteiro fresco, em setembro de 2011, era 
vendido em média a $\mathrm{R} \$ 3,11$ na safra, e na entressafra o valor negociado praticamente dobra. Porém, os maiores rendimentos são obtidos com os produtos oriundos do beneficiamento, como por exemplo, o camarão descascado salgado, vendido em média a $\mathrm{R} \$ 7,22$ e $\mathrm{R} \$ 13,25 / \mathrm{kg}$ na safra e entressafra, respectivamente (Tabela 3). A variação sazonal dos preços de venda do camarão é comum na área de jusante pois está vinculado a abundância e escassez do produto.

Tabela 3 - Relação dos preços (R\$) mínimo (mín.), médio (méd.) e máximo (máx.) por quilograma de camarão-daamazônia durante a safra (S) e entressafra (ES), na área a jusante da UHE Tucuruí no período de setembro a novembro de 2011.

\begin{tabular}{lcccccccc}
\hline Período & \multicolumn{2}{c}{$\begin{array}{c}\text { Inteiro } \\
\text { fresco }\end{array}$} & \multicolumn{2}{c}{$\begin{array}{c}\text { Descascado } \\
\text { refrigerado }\end{array}$} & \multicolumn{2}{c}{$\begin{array}{c}\text { Inteiro } \\
\text { salgado }\end{array}$} & \multicolumn{2}{c}{$\begin{array}{c}\text { Descascado } \\
\text { salgado }\end{array}$} \\
\cline { 2 - 10 } & $\mathrm{S}$ & $\mathrm{ES}$ & $\mathrm{S}$ & $\mathrm{ES}$ & $\mathrm{S}$ & $\mathrm{ES}$ & $\mathrm{S}$ & $\mathrm{ES}$ \\
\hline $\mathrm{N}$ & 89 & 51 & 9 & 7 & 16 & 10 & 19 & 16 \\
\hline mín. & 1,00 & 3,00 & 3,00 & 5,00 & 3,00 & 8,30 & 3,70 & 6,20 \\
méd. & 3,11 & 6,02 & 5,94 & 8,86 & 5,93 & 13,51 & 7,22 & 13,25 \\
máx. & 8,00 & 10,00 & 10,00 & 13,00 & 8,30 & 16,70 & 12,00 & 20,00 \\
\hline $\mathrm{DP}$ & 1,59 & 1,67 & 2,32 & 2,91 & 2,17 & 3,66 & 2,25 & 3,86 \\
\hline $\mathrm{CV}$ & 51,29 & 27,77 & 39,13 & 32,87 & 36,71 & 27,12 & 31,29 & 29,14 \\
\hline
\end{tabular}

N - Número de pescadores; DP - desvio padrão; CV - coeficiente de variação.

Com relação as dificuldades para comercializar o crustáceo, os entrevistados apontam, dentre tantas, a infraestrutura do ponto de venda que em sua maioria funciona sem as mínimas condições necessárias para expor o produto aos consumidores, pois no geral, são ambientes deficientes de infraestrutura e condições sanitárias adequadas.

Outro ponto citado, foi a demora na comercialização, pois de acordo com os pescadores, ao término da manhã os camarões ficam com aparência e odor desagradável. Na safra a situação agrava-se, pois, o número de vendedores também dobra nesse período, aumentando a oferta do produto e consequentemente a concorrência entre os comerciantes. Para evitar prejuízos, com a deterioração do pescado, os pescadores são obrigados a reduzir o valor do produto ofertado.

Esses atores sociais são detentores de um amplo conhecimento tradicional refletindo, portanto, não somente a respeito dos problemas enfrentados, mas também sobre as possíveis formas para solucioná-los. Dentre as medidas apontadas, a construção de um espaço físico adequado e higiênico foi o mais citado. Mas também relataram sobre a importância de um comprador exclusivo ou a instalação de uma pequena fábrica beneficiadora de camarão na região que adquirissem o produto a um preço justo pois, segundo eles, o camarãoda-amazônia quando comparado com outros camarões, também de importância na cultura gastronômica paraense, é bastante desvalorizado.

A comercialização, o camarão inteiro fresco (in natura) foi a mais frequente $(46,2 \%)$ em toda área, seguido pela cauda descascada $(23,9 \%)$. No município de Mocajuba, todos os pescadores comercializavam o camarão na forma in natura. Limoeiro do Ajuru foi o único município onde se encontrou os cinco tipos de camarões comercializados na região (in natura inteiro, in natura descascado, cozido inteiro, cozido descascado e tipo salgadinho) (Aviz; Cintra; Santos; Silva: Rebello; Martins \& Nogueira, 2020).

Todos os pescadores entrevistados informaram que vendem sua produção à vista ou, no máximo, há um acordo verbal com o intermediário, para pagamento posterior. Quando questionados se consideravam que os preços praticados para a venda do camarão, seja no atacado ou varejo era justo, $53 \%$ consideram que não. Segundo os mesmos, esta percepção é proveniente do baixo valor pago pelo produto tanto no varejo como no atacado (Aviz; Cintra; Santos; Silva: Rebello; Martins \& Nogueira, 2020).

A preferência dos pescadores pelas feiras/mercados para comercialização do crustáceo se deve, provavelmente, ao fato do local ser um importante espaço de transações comerciais e consequente aglomeração de pessoas, o que possibilita a venda do produto diretamente ao consumidor. As pescadoras da ilha Trambioca (Barcarena, Estado do Pará) também preferem vender o produto diretamente ao consumidor em função da elevação dos lucros (Simonian, 2006).

Mas, assim como em outras atividades produtivas, o atravessador também está presente na pesca (Cintra; Aviz; Carvalho; Juras: Teshima \& Ogawa, 2007) e na área à jusante da UHE Tucuruí não é diferente, 
principalmente em Limoeiro do Ajuru. Talvez, o principal produto (camarão descascado salgado "salgadinho") elaborado na região, que não se decompõe com facilidade podendo, ser estocado por mais tempo, até que a venda se torne viável, justifique a forte presença de atravessadores no município. Em outras regiões do Estado, como na ilha do Mosqueiro o atravessador predomina chegando a negociar cerca de $90 \%$ da produção (Silva et al. 2012).

As informações sobre variação sazonal dos preços do camarão apontado no referido estudo divergem dos resultados expostos por Silva et al. (2012) para a Ilha do Mosqueiro, onde os maiores valores de mercado são registrados na alta temporada do turismo $\mathrm{Na}$ Ilha, que coincide com a safra do recurso, ou seja, a variação do preço do camarão está relacionado com a incidência de turistas e não com a abundância/escassez do recurso.

Ressalta-se ainda, que o camarão-da-amazônia é um produto altamente perecível estando, portanto, susceptível a deterioração por micro-organismos que podem ter sua ação potencializada, quando o produto é manipulado e exposto de maneira inadequada. Desta forma, a alta temperatura ambiente, associada ao tempo de comercialização, podem aferir a qualidade do crustáceo e acarretar perdas financeiras para o pescador.

A classificação dos camarões por tamanho é comum também nas feiras livres e pontos de comercialização. Essa classificação resulta em valorização no preço de venda, contudo, a maioria dos pescadores entrega o camarão sem seleção, pois acredita que o tempo gasto no processo seria melhor utilizado em novas capturas. O esforço aplicado na retirada da casca favorece a agregação de valor de comercialização, independente do período do ano e de estarem na forma in natura ou salgada (Silva, Silva, Herrmann, Araújo \& Cintra, 2016).

As principais atividades produtivas desenvolvidas pelos pescadores e suas famílias são a pesca de camarão e peixe, sendo destinados ao consumo e a venda. Porém, este crustáceo contribui somente com $15,4 \%$ da renda média mensal, sendo complementada com os rendimentos oriundos de outras atividades produtivas e dos programas sociais do governo federal (Araújo; Silva; Romão-Junior; Cintra \& Santos, 2014).

O pescador artesanal utiliza-se de conhecimentos tradicionais, adquiridos por meio do tempo repassados de pais para filhos e conhecimentos também adquiridos de forma empírica em suas atividades diárias sempre com estreita relação com o meio ambiente. Os apetrechos voltados a pesca do camarão-da-amazônia são confeccionados utilizando materiais naturais, como fibras e cipós, como é o caso do matapi, que é o apetrecho utilizado por todos os entrevistados neste estudo (Cintra; Juras; Silva; Tenório \& Ogawa, 2009).

\section{Considerações Finais}

A pesca camarão-da-amazônia é expressiva em todo Estado Pará, como uma atividade eminentemente artesanal, com produção que varia muito ao longo do ano, beneficiamento tradicional e familiar e geralmente comercializado localmente.

É um dos principais recursos pesqueiros da área à jusante da UHE Tucuruí, sendo explorado para fins de subsistência e comercial, com destaque de produção para o município de Mocajuba. Sua pesca é desenvolvida durante o ano todo com picos de produção nos meses de maio e agosto, coincidindo com a reprodução e o recrutamento da espécie, respectivamente.

A safra sofre pequenas modificações entre os municípios. Baião, Mocajuba e Cametá, nestes municípios ocorre no período chuvoso e a entressafra, na estação menos chuvosa (verão). Enquanto em Limoeiro do Ajuru, a safra incide no verão e a entressafra no inverno.

Os pescadores da região, contribuem com a preservação da espécie ao parar a pesca no período de recrutamento, no entanto, o incremento de pescadores durante a safra contribui com intensificação da pesca. do recurso.

O camarão inteiro fresco é o principal produto comercializado, porém os maiores rendimentos derivam do beneficiamento do crustáceo, principalmente nas formas de camarão salgado inteiro ou cauda descascada.

Mesmo apresentando demanda de mercado, o camarão-da-amazônia ainda é pouco valorizado, contudo, a receita obtida com a venda dos produtos tem sido essencial para a vida dos ribeirinhos do baixo Tocantins.

Desta forma, destaca-se a importância em fortalecer a produção familiar por meio de políticas de fomento ao empreendedorismo, mais especificamente às micro e pequenas empresas "existentes" ao longo do baixo rio Tocantins, haja vista, que os pescadores de camarão são proprietários de seus meios de produção com participação ativa nas etapas de pesca, beneficiamento e venda do recurso, sob cooperação da família. Mas, para alcançar o desenvolvimento social é necessário levar em consideração o estado do estoque dos recursos. 


\section{Referências}

Araújo, M. V. L. F., Silva, K. C. A., Romão Junior, J. G., Cintra, I. H. A. \& Santos, M. A. S. (2014). Socioeconomia e percepção ambiental dos pescadores de camarão-da-amazônia a jusante da UHE Tucuruí, Pará, Brasil. Amazônia: Ciência \& Desenvolvimento. 10(19), 149-160.

Araújo, M. V. L. F., Silva, K. C. A, Silva, B. B., Ferreira, I. L. S. \& Cintra, I. H. A. (2014). Pesca e procedimentos de captura do camarão-da-amazônia à jusante de uma usina hidrelétrica na Amazônia brasileira. Biota Amazônia. 4(2), 102-112.

Aviz, J. S., Cintra, I. H. A., Santos, M. A. S., Silva, K. C. A., Rebello, F. K., Martins, C. M. \& Nogueira, A. S. (2020). A pesca artesanal do camarão-da-amazônia em municípios a jusante da usina hidrelétrica de Tucuruí: características tecnológicas, socioeconômicas e ambientais. Research, Society and Development. 9(7), 1-21 e62973747.

Cintra, I. H. A., Juras, A. A., Andrade, J. A. C. \& Ogawa, M. (2007). Caracterização dos desembarques pesqueiros na área de influência da usina hidrelétrica de Tucuruí, estado do Pará, Brasil. Boletim Técnico Científico do Cepnor, 7(1), 135-152.

Cintra, I. H. A., Flexa, C. E., Silva, M. B., Araújo, M. V. L. F. \& Silva, K. C. A. (2013). A pesca no reservatório da usina hidrelétrica de Tucuruí, região amazônica, Brasil: aspectos biológicos, sociais, econômicos e ambientais. Acta of Fisheries and Aquatic Resources. 1(1), 57-78.

Cintra, I. H. A., Juras, A. A., Silva, K. C. A., Tenório, G. S. \& Ogawa, M. (2009). Apetrechos de pesca utilizados no reservatório da usina hidrelétrica de Tucuruí (Pará, Brasil). Boletim Técnico Científico do Cepnor, 9(1), 67-79.

Cintra, I. H. A., Aviz, J. S., Carvalho, R. C. A., Juras, A. A., Teshima, P. R. \& Ogawa, M. (2007). A cadeia produtiva da pesca artesanal na área de influência da usina hidrelétrica de Tucuruí, estado do Pará, Brasil. Boletim Técnico Científico do Cepnor. 7(1), 97-114.

Fisch, G. F., Januário, M. \& Senna, R. C. (1990). Impacto ecológico em Tucuruí (PA): climatologia. Acta Amazonica. 20(1), 49-60.

Fonteles-Filho, A. A. (2011). Oceanografia, biologia e dinâmica populacional de recursos pesqueiros. Fortaleza: Expressão Gráfica e Editora, CE.

Juras, A. A., Cintra, I. H. A. \& Ludovino, R. M. R. (2004). A pesca na área de influência da usina hidrelétrica de Tucuruí, estado do Pará. Boletim Técnico Científico do Cepnor. 4(1), 77-88.

Lima, J. F., Cintra, I. H. A., Bastos, A. M., Damasceno, L. F., Montagner, D. \& Varela, E. S. (2016). Caracterização do sistema pesqueiro de produção do camarão-da-amazônia no estuário amazônico. (Documentos / Embrapa Amapá) Macapá: Embrapa.

Lima, J. F.; Santos, T. S. (2014). Aspectos econômicos e higiênico-sanitários da comercialização de camarões em feiras livres de Macapá e Santana, Estado do Amapá. Biota Amazônia, 4 (1): 1-8,

MPA - Ministério da Pesca e Aquicultura (2010). Boletim estatístico da pesca e aquicultura: Brasil 20082009. Brasília: MPA.

Mérona, B., Santos, G. M., Juras, A. A. \& Cintra, I. H. A. C. (2010). Os peixes e a pesca no baixo rio Tocantins: 20 anos depois da UHE Tucuruí. Eletronorte/IRD/INPA/UFRA.

Odinetz-Collart, O. (1988). Aspectos ecológicos do camarão Macrobrachium amazonicum (Heller, 1862) no baixo Tocantins (PA-Brasil). Memoria de la Sociedad de Ciencias Naturales La Salle. 158(1), 341-353.

Odinetz-Collart, O. (1993). Ecologia e potencial pesqueiro do camarão-canela, Macrobrachium amazonicum, na bacia Amazônica. In: E. J. G Ferreira et al. (Eds.). Bases científicas para estratégias de preservação e desenvolvimento da Amazônia: fatos e perspectivas (pp.147-166). Manaus: AM.

Pereira A. S., Shitsuka, D. M., Parreira. F. J. \& Shitsuka, R. (2018). Metodologia da pesquisa científica. [ebook]. Santa Maria. Ed. UAB/NTE/UFSM. Disponível em: 10 de junho de 2020. https://repositorio.ufsm.br/bitstream/handle/1/15824/Lic_Computacao_Metodologia-PesquisaCientifica.pdf?sequence $=1$ 
Sanches, F. \& Fisch, G. (2005). As possíveis alterações microclimáticas devido a formação do lago artificial da hidrelétrica de Tucuruí-PA. Acta Amazonica, 35(1), 41-50.

Santos, G. M. \& Mérona, B. (1996). Impactos imediatos da UHE Tucuruí sobre as comunidades de peixes e a pesca. In: S. B. Magalhães, E. R. de Castro \& R. C. Britto (Ed.). Energia na Amazônia (pp. 251-258). Belém: MPEG.

Silva, B. B., Bentes, B., Cañete, V. R., Pereira, L. J. G., Martinelli-Lemos, J. M. \& Isaac, V. (2012). Descrição socioeconômica da pesca do camarão Macrobrachium amazonicum (Heller, 1862) (Decapoda: Palaemonidae) em um estuário da costa Norte do Brasil: o caso da ilha do Mosqueiro (PA). Boletim do Laboratório de Hidrobiologia. 25(1), 31-48.

Silva, K. C. A., Cintra, I. H. A. \& Muniz, A. P. M. (2005). Aspectos bioecológicos de Macrobrachium amazonicum (Heller, 1862) a jusante do reservatório da hidrelétrica de Tucuruí-Pará. Boletim Técnico Científico do Cepnor, 5(1), 55-71.

Silva, M. B., Silva, K. C. A., Herrmann, M., Araújo, M. V. L. F. \& Cintra, I. H. A. (2016). Mulheres pescadoras de camarão-da-amazônia a jusante da usina hidrelétrica de Tucuruí, Amazônia, Brasil. Revista Brasileira de Engenharia de Pesca. 7(2), 15-33.

Simonian, L. T. L. (2006). Pescadoras de camarão: gênero, mobilização e sustentabilidade na ilha Trambioca, Barcarena, Pará. Boletim do Museu Paraense Emílio Goeldi. 1(2), 35-52. 